\title{
What would be the annual cost savings if fewer screws were used in adolescent idiopathic scoliosis treatment in the US?
}

\author{
A. Noelle Larson, MD, ${ }^{1}$ David W. Polly Jr., MD, ${ }^{2}$ Stacey J. Ackerman, MSE, PhD, ${ }^{3}$ \\ Charles G. T. Ledonio, MD, ${ }^{2}$ Baron S. Lonner, MD, ${ }^{4}$ Suken A. Shah, MD, ${ }^{5}$ John B. Emans, MD, ${ }^{6}$ \\ B. Stephens Richards III, MD, ${ }^{7}$ and the Minimize Implants Maximize Outcomes Study Group
}

\begin{abstract}
${ }^{1}$ Department of Orthopedic Surgery, Mayo Clinic, Rochester, Minnesota; ${ }^{2}$ Department of Orthopaedic Surgery, University of Minnesota, Minneapolis, Minnesota; ${ }^{3}$ Covance Market Access Services Inc., San Diego, California; ${ }^{4}$ Mount Sinai Beth Israel Hospital, Department of Orthopedic Surgery, New York, New York; ${ }^{5}$ Department of Orthopaedic Surgery, Alfred I. DuPont Hospital for Children, Wilmington, Delaware; ' ${ }^{6}$ Department of Orthopaedic Surgery, Children's Hospital, Boston, Massachusetts; and ${ }^{7}$ Department of Orthopaedic Surgery, Texas Scottish Rite Hospital for Children, Dallas, Texas
\end{abstract}

OBJECTIVE There is substantial heterogeneity in the number of screws used per level fused in adolescent idiopathic scoliosis (AIS) surgery. Assuming equivalent clinical outcomes, the potential cost savings of using fewer pedicle screws were estimated using a medical decision model with sensitivity analysis.

METHODS Descriptive analyses explored the annual costs for 5710 AIS inpatient stays using discharge data from the 2009 Kids' Inpatient Database (Healthcare Cost and Utilization Project, Agency for Healthcare Research and Quality), which is a national all-payer inpatient database. Patients between 10 and 17 years of age were identified using the ICD9-CM code for idiopathic scoliosis (737.30). All inpatient stays were assumed to represent 10-level fusions with pedicle screws for AIS. High screw density was defined at 1.8 screws per level fused, and the standard screw density was defined as 1.48 screws per level fused. The surgical return for screw malposition was set at $\$ 23,762$. A sensitivity analysis was performed by varying the cost per screw $(\$ 600-\$ 1000)$ and the rate of surgical revisions for screw malposition $(0.117 \%-0.483 \%$ of screws; $0.8 \%-4.3 \%$ of patients). The reported outcomes include estimated prevented malpositioned screws (set at 5.1\%), averted revision surgeries, and annual cost savings in 2009 US dollars, assuming similar clinical outcomes (rates of complications, revision) using a standard- versus high-density pattern.

RESULTS The total annual costs for 5710 AIS hospital stays was $\$ 278$ million ( $\$ 48,900$ per patient). Substituting a high for a standard screw density yields 3.2 fewer screws implanted per patient, with 932 malpositioned screws prevented and 21 to 88 revision surgeries for implant malposition averted, and a potential annual cost savings of $\$ 11$ million to $\$ 20$ million ( $4 \%-7 \%$ reduction in the total cost of AIS hospitalizations).

CONCLUSIONS Reducing the number of screws used in scoliosis surgery could potentially decrease national AIS hospitalization costs by up to $7 \%$, which may improve the safety and efficiency of care. However, such a screw construct must first be proven safe and effective.

http://thejns.org/doi/abs/10.3171/2015.4.SPINE131119

KEY WORDS screw; implant density; scoliosis; curve correction; outcomes; malposition; deformity

$\mathrm{S}$ IGNIFICANT heterogeneity exists in the number and distribution of pedicle screws used in the treatment of adolescent idiopathic scoliosis (AIS). ${ }^{7,43,48}$ Pedicle screws are the state-of-the-art implant for the surgical correction of scoliosis..$^{10,13,31}$ Implant density is defined as the number of implants per level fused. Often, pedicle screws are placed bilaterally at every vertebra included in the pos- terior spinal fusion, representing a maximum density pattern of 2.0 anchors per vertebral level fused. While some practitioners recommend far fewer screws, with implant densities as low as 1.04 screws per level, ${ }^{21,32,47,48}$ the optimum number and configuration of screw placement for the treatment of AIS has not been established. .54 $^{5}$

Compared with previous implants, pedicle screws offer

ABBREVIATIONS AIS = adolescent idiopathic scoliosis; KID = Kids' Inpatient Database 
significant advantages, including a lower revision surgery rate and higher pullout strength than a hybrid or hook-rod construct. ${ }^{10,14,16,17,25,26,28,31,33,37,42,48,49}$ Pedicle screws may obviate the need for anterior fusion. ${ }^{17}$ Also, improved pulmonary function, balance, patient-reported appearance scores, and maintenance of correction over time have been reported. ${ }^{16,17,45,53} \mathrm{~A}$ recent structured literature review reveals a wide variety in the mean implant density reported in clinical practice..$^{39}$ Implant densities varied from 1.04 to 2.0 screws per level fused, while in the same studies the mean percentage of major Cobb angle correction only varied from $64 \%$ to $70 \% .40$

With the introduction of pedicle screws, the cost of scoliosis surgery has increased due to high implant expenses, ${ }^{41}$ which comprise on average $29 \%$ of the total hospital costs incurred during primary scoliosis surgery. ${ }^{24}$ Decreasing the number of implants used may lower the surgical implant cost. If low-density constructs are shown to be safe and clinically equivalent to higher density constructs, fewer pedicle screws could be used, which may have significant benefits in terms of surgical efficiency and the effective use of health care resources.

Furthermore, some screws are malpositioned. Decreasing the number of screws used may conceivably reduce the number of malpositioned screws. In pediatric patients, up to $1.8 \%$ to $9.0 \%$ of screws are malpositioned. ${ }^{30,51}$ Assuming that on average 10 spinal levels are fused with 2 screws placed per level, this represents up to 1 to 2 malpositioned screws per patient. ${ }^{29,30,35}$ The implications of asymptomatic malpositioned screws are unknown. However, there are rare reports of catastrophic events resulting from screw malpositioning, including vascular and neurological injury. ${ }^{11,19,37,44,46,47,55}$ Due to poor data regarding the incidence of such rare events, it is difficult to include these events in a medical model. However, return to surgery for implant malposition is well-reported in the literature, affecting up to $0.66 \%$ to $4.3 \%$ of patients. ${ }^{3,7,14,20,38}$ Thus, if clinically equivalent, using fewer screws overall may incrementally improve patient safety with fewer malpositioned screws and thus fewer returns to the operating room for screw malposition. This may subsequently reduce the cost of scoliosis surgery due to fewer surgical returns for implant malposition.

We undertook this study to determine the effects on US health care spending if surgeons decreased the numbers of screws used in the surgical management of AIS. We used the Kids' Inpatient Database (KID) to estimate the anticipated annual US cost savings from changing from a high- to low-density screw pattern, including both implant costs and returning to the operating room for screw malposition as components in the potential cost savings. This paper describes the estimated economic effects of a practice change to using fewer screws, assuming that this results in no change in patient outcomes.

\section{Methods}

We undertook descriptive analyses to explore the annual costs for AIS inpatient stays using discharge data from the 2009 KID (Healthcare Cost and Utilization Project, Agency for Healthcare Research and Quality), which is a national all-payer hospital inpatient database (https://www. hcup-us.ahrq.gov/kidoverview.jsp). The analysis was performed from a payer's perspective. Since many of the reported studies did not provide a year for the cost estimates, no conversion to 2009 dollars was performed. Patients between 10 and 17 years of age with an AIS inpatient stay were identified using ICD-9-CM diagnosis code 737.30, which was recorded in the primary diagnosis field. This yielded 5710 hospitalizations. All AIS hospital admissions were assumed to be due to primary spinal fusion for the treatment of AIS. All surgeries were assumed to be posterior instrumentation with pedicle screw fixation over 10 fusion levels, which is the commonly reported mean length of AIS fusion (Table 1). ${ }^{4,8,28,24,26}$ All spinal fusions were assumed to be carried out exclusively with pedicle screws.

Several implant density patterns were considered, including the current standard implant density (1.48 implants per level fused), high implant density (1.8 implants per level fused), low implant density (1.4 implants per level fused), very low implant density (1.06 implants per level fused), and maximum implant density (2.0 implants per level fused) (Fig. 1). Each vertebral level typically has 2 pedicles that could potentially be instrumented. In the literature, the lowest mean implant density reported to have successful results is 1.06 screws per level fused. $21,32,34,50$ Thus, 1.06 screws per level fused was then defined as very low implant density. Multiple models were considered. For the purposes of this paper, however, the primary model discussed was changed from high implant density (1.8 screws per level fused) to standard implant density (1.48 screws per level fused). We selected this case scenario because this represents a modest change in practice. Likely, most surgeons accustomed to a high implant density constructs would be willing to use 3 to 4 fewer screws per construct. The current mean implant density used among US surgeons is unknown.

The cost of return to the operating room for screw malposition was set at $\$ 23,762^{2,39,56}$ (Table 2). There is only 1 paper that provides cost data regarding screw revision surgery. ${ }^{56}$ Other citations describe the cost of revision lumbar decompression and fusion surgery, but this is likely more expensive than straightforward screw revision.,239 Thus, the lower end of the cost spectrum was used in our model for the cost of returning to the operating room for screw revision. A sensitivity analysis was performed by varying the cost per screw ( $\$ 600-\$ 1000$ per screw). The rate of return to surgery for screw malposition also varied from $0.117 \%$ to $0.483 \%$ of screws placed (Table 3). . $^{3,14,20,27,36,38}$ The reported outcomes include the anticipated cost savings from implant costs, potential number of malpositioned screws prevented, and cost savings from averted returns to surgery for screw malposition. The total annual cost savings (in 2009 US dollars) were estimated based on the implant costs and averted returns to surgery. No attempt was made to assess the cost of catastrophic screw malposition that resulted in vascular or neurological compromise. No assessment was made for changes in surgical time due to fewer screws placed at the time of surgery. Clinical outcomes and complications were assumed to be equivalent irregardless of implant density.

Since only limited data sets were used for this study, institutional review board approval was not required. This 
TABLE 1. Cited references for the numbers of levels fused in patients with AIS

\begin{tabular}{|c|c|c|c|c|}
\hline Authors \& Year & Study Type & Surgery & $\begin{array}{l}\text { No. of } \\
\text { Patients }\end{array}$ & $\begin{array}{l}\text { No. of Levels } \\
\text { Fused* }\end{array}$ \\
\hline Gebhart et al., 2014 & Retrospective review & Posterior spinal fusion for AIS, all curve patterns & 119 & 10.7 (range 5-15) \\
\hline $\begin{array}{l}\text { Kamerlink et al., } \\
2010\end{array}$ & Retrospective review & Posterior spinal fusion for AIS, all curve patterns & 111 & $10.5 \pm 1.9$ \\
\hline Arlet et al., 2009 & Retrospective review & $\begin{array}{l}\text { Posterior spinal fusion for AIS, Lenke } 1 \text { and } 2 \text { curve } \\
\text { patterns }\end{array}$ & 40 & 10.3 \\
\hline Bharucha et al., 2013 & Retrospective review & Posterior spinal fusion & 91 & $9.0 \pm 1.6$ \\
\hline Kim et al., 2006 & Retrospective review & Posterior spinal fusion for AIS & 58 & $11.7 \pm 1.6$ \\
\hline
\end{tabular}

* The mean, mean \pm standard deviation, or mean (range) is shown.

study was funded by the Orthopaedic and Research Education Foundation as part of a planning grant for the Minimize Implants Maximize Outcomes Study Group.

\section{Results}

According to the $2009 \mathrm{KID}$, the total annual costs for 5710 AIS hospital stays was $\$ 278$ million. This represents a cost of $\$ 48,900$ per patient. If $29 \%$ of the surgical costs are secondary to implants, as reported by Kamerlink et al., ${ }^{24}$ this represents $\$ 81$ million dollars spent on implants. Due to the limited data contained in KID, the type and number of implants used are unknown. Modeling, however, was undertaken to estimate the cost savings if the practice patterns changed.

The results of medical modeling with sensitivity analysis are reported with the estimated national and individual cost savings for changes in a variety of screw densities (Table 4). We estimated that changing from a high-density (1.8 screws per level fused) to a standard screw pattern (1.48) would result in $\$ 10$ million to $\$ 18$ million in annual US health care savings from implant costs alone. By including the costs of the predicted 21 to 88 averted surgi- cal returns due to malpositioned screws, this would reduce costs by $\$ 11$ million to $\$ 20$ million annually. This would effectively reduce the total US cost of AIS surgery by $4 \%$ to $7 \%$. If even fewer screws were used, this would obviously result in greater potential cost savings (Figs. 2 and 3).

\section{Discussion}

This study reports the anticipated cost reduction from a payer's perspective if fewer screws are used for AIS surgery. This model assumes that the complications, clinical results, and patient recovery are equivalent between low implant density and high implant density cohorts. This hypothesis has not yet been proven. This study was undertaken to evaluate the anticipated payer cost savings if a low-density pedicle screw construct could be safely substituted for a high- or maximum-density construct.

\section{Characteristics of the Medical Model}

Significant uncertainty and assumptions are required for any medical model. In this study, some of the uncertainty in the model parameters was accounted for by using a sensitivity analysis to evaluate the reported variability in
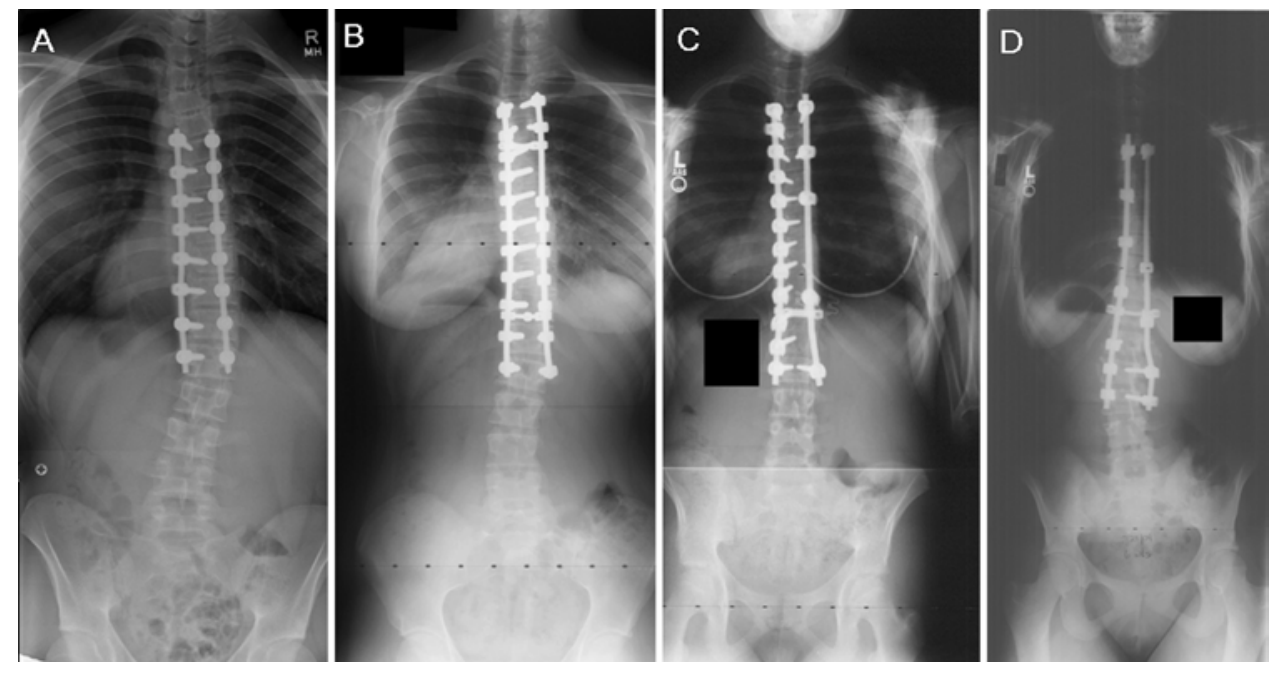

FIG. 1. Implant density is defined as the number of screws, rods, and hooks per level fused. These radiographs show examples of constructs with various implant densities. A: Maximum-density construct ( 2.0 screws per level fused). B: High-density construct (1.8 screws per level fused). C: Low-density construct (1.4 screws per level fused). D: Minimum-density construct (1.06 screws per level fused). 
TABLE 2. Cited references for the cost of revision spine surgery

\begin{tabular}{|c|c|c|c|c|}
\hline Authors \& Year & Study Type & Surgery & $\begin{array}{c}\text { No. of } \\
\text { Patients }\end{array}$ & Cost $^{*}$ \\
\hline Parker et al., 2012 & Retrospective review & Revision lumbar fusion procedure & 150 & $\$ 32,915$ (range $\$ 24,935-\$ 63,769$ ) \\
\hline Watkins et al., 2010 & Cost analysis & Screw revision & $\begin{array}{c}\text { Hospital } \\
\text { data }\end{array}$ & $\$ 23,762$ \\
\hline Adogwa et al., 2012 & Retrospective review & Revision lumbar fusion procedure & 42 & $\$ 21,060 \pm 4,459$ \\
\hline Adogwa et al., 2015 & Retrospective review & Revision fusion for pseudoarthrosis & 47 & $\$ 23,865 \pm 270$ \\
\hline
\end{tabular}

* The mean, mean \pm standard deviation, or mean (range) is shown.

the rates of return to the operating room due to screw malposition and the costs of pedicle screws. The results are reported as a range and take into account the variability in screw costs and rates of screw malposition.

\section{Rate of Screw Malposition}

One may argue that decreasing the overall number of pedicle screws may not decrease the number of malpositioned screws. We would argue that if only a certain number of screws are to be used, surgeons would be most likely to place screws in the most easily accessible, reliable pedicles. If the goal of surgery is only to instrument $50 \%$ of the pedicles for a 1.0 implant density, surgeons may be more likely to not instrument a pedicle if the initial trajectory is not satisfactory or if the pedicle appears narrow and highly cortical on preoperative imaging. The highest rate of screw malposition is typically at the levels where the pedicles are smallest (T-6, T-7, and T-8) ${ }^{29}$ The optimum strategic array of pedicle screws, however, has not been determined in the literature, and wide surgeon variability exists in terms of both the number and chosen array of screw placement. ${ }^{5,6,40}$ Thus, this study made the reasonable assumption that, should the overall number of screws decrease, the overall rate of malpositioning would proportionately decrease. We acknowledge that the data on this topic are limited.

\section{Limitations of the Medical Model}

Additional parameters, however, were not included in the model, including operative time, fluoroscopy time, and the cost to the payer from asymptomatic malpositioned screws. Fewer pedicle screws have been shown to result in a shorter operative time and decreased radiation if intraoperative fluoroscopy is used..$^{52}$ The minimum screw density pattern reduces the operative time (mean 145 minutes vs 177 minutes for 10-level fusion) required for screw placement. ${ }^{12,22}$ Shorter operative time may conceivably decrease the rate of infections and other medical complications. ${ }^{12}$ However, due to the lack of reliable available data, these factors were not included in the model.

Similarly, the payer costs for asymptomatic malpositioned pedicle screws were not included in the model. At this time, malpositioned screws are thought to be well tolerated, but long-term outcomes data are not available for determining the cost or significance of the medial and lateral screw violations reported for $1.8 \%$ to $9 \%$ of screws placed for idiopathic scoliosis..$^{30,51}$ The adult literature does reveal several case reports resulting in delayed vascular

TABLE 3. Cited references regarding return to surgery

\begin{tabular}{|c|c|c|c|c|c|}
\hline Authors \& Year & Study Type & Surgical Indication & $\begin{array}{c}\% \text { Malpositioned } \\
\text { Screws (\% of Patients } \\
\text { w/ Malpositioned } \\
\text { Screw) }\end{array}$ & $\begin{array}{l}\text { Screws Resulting in } \\
\text { Return to OR }\end{array}$ & $\begin{array}{l}\text { Patients Returning to OR } \\
\text { for Screw Malposition }\end{array}$ \\
\hline Amiot et al., 2000 & $\begin{array}{l}\text { Retrospective com- } \\
\text { parison }\end{array}$ & Spine fusion & $\begin{array}{l}0.6 \% \mathrm{w} / \text { fluoroguidance } \\
\& 0 \% \mathrm{w} / \text { fluoro } \\
\text { navigation }\end{array}$ & $\begin{array}{l}5 / 544 \text { fluoro screws } \\
\quad(0.9 \%)\end{array}$ & $\begin{array}{l}\text { 5/100 w/ fluoro guidance } \\
(5 \%) \& 0 / 50 \mathrm{w} / \text { fluoro } \\
\text { navigation }(0 \%)\end{array}$ \\
\hline Belmont et al., 2002 & Retrospective review & $\begin{array}{l}\text { Spine fusion, fluoro } \\
\text { guidance }\end{array}$ & $1-2 \%(10 \%)$ & $2 / 399$ screws $(0.5 \%)$ & $4 \%$ (2/47 patients) \\
\hline Koktekir et al., 2014 & Retrospective review & $\begin{array}{l}\text { Spine fusion, fluoro } \\
\text { assisted }\end{array}$ & $2.2 \%(10.6 \%)$ & $15 / 1218$ screws $(1.2 \%)$ & $7.5 \%$ (15/198 patients) \\
\hline $\begin{array}{l}\text { Motiei-Langroudi et al., } \\
2015\end{array}$ & Prospective study & Spine fusion & $2.3 \%$ & $\begin{array}{c}1 / 770 \text { screws } \\
(0.13 \%)\end{array}$ & $0.8 \%$ (1/114 patients) \\
\hline Parker et al., 2011 & Retrospective review & Spine fusion, freehand & $1.7 \%(9.0 \%)$ & $8 / 6818(0.117 \%)$ & $0.8 \%$ (8/964 patients) \\
\hline Hicks et al., 2010 & Systematic review & AIS & $4.2 \%(11 \%)$ & $12 / 4570(0.26 \%)$ & $0.66 \%$ (11/1666 patients) \\
\hline Di Silvestre et al., 2007 & Retrospective review & $\begin{array}{l}\text { Scoliosis patients, pri- } \\
\text { marily AIS, mini } \\
\text { laminotomy }\end{array}$ & $1.7 \%(11.3 \%)$ & $\begin{array}{l}5 / 1035 \text { thoracic } \\
\text { screws placed } \\
(0.483 \%)\end{array}$ & $4.3 \%$ (5/115 patients) \\
\hline
\end{tabular}

Fluoro = fluoroscopic; OR = operating room 
TABLE 4. Analysis of total US cost savings in changing from high-density to low-density pedicle screw constructs in 2009 dollars*

\begin{tabular}{|c|c|c|c|c|c|c|}
\hline $\begin{array}{l}\text { Change in Implant Density } \\
\text { (Screws Per Level Fused) }\end{array}$ & $\begin{array}{c}\text { Screw } \\
\text { Reduction } \\
\text { Per Patient }\end{array}$ & $\begin{array}{l}\text { Mean Cost } \\
\text { Savings Per } \\
\text { Patient }\end{array}$ & $\begin{array}{l}\text { Inpatient National Cost Savings } \\
\text { (Implant Costs) }\end{array}$ & $\begin{array}{c}\% \text { Reduction } \\
\text { from Current } \\
\text { Costs }\end{array}$ & $\begin{array}{l}\text { Prevented Return } \\
\text { to OR for } \\
\text { Malposition } \\
(0.117-0.483 \% \text { of } \\
\text { screws) }\end{array}$ & $\begin{array}{c}\text { Prevented } \\
\text { Malpositioned } \\
\text { Screws }\end{array}$ \\
\hline High (1.8) $\rightarrow$ standard (1.48) & 3.2 & $\$ 2000-\$ 3500$ & \$11M-\$20M (\$10M-\$18M) & $4 \%-7 \%$ & $21-88$ & 932 \\
\hline Standard (1.48) $\rightarrow$ very low (1.06) & 4.2 & $\$ 2600-\$ 4700$ & \$15M-\$27M (\$14M-\$24M) & $5 \%-10 \%$ & $28-116$ & 1223 \\
\hline High (1.8) $\rightarrow$ very low (1.06) & 7.4 & $\$ 4600-\$ 8200$ & $\$ 26 \mathrm{M}-\$ 47 \mathrm{M}(\$ 24 \mathrm{M}-\$ 42 \mathrm{M})$ & $9 \%-17 \%$ & 49-204 & 2255 \\
\hline $\operatorname{High}(1.8) \rightarrow \operatorname{low}(1.4)$ & 4.0 & $\$ 2511-\$ 4459$ & $\$ 14 M-\$ 26 M(\$ 14 M-\$ 23 M)$ & $5 \%-9 \%$ & $26-110$ & 1165 \\
\hline Maximum $(2.0) \rightarrow$ very low (1.06) & 9.4 & $\$ 5900-\$ 10,000$ & $\$ 34 M-\$ 60 M(\$ 32 M-\$ 54 M)$ & $12 \%-22 \%$ & $63-260$ & 2737 \\
\hline
\end{tabular}

$\mathrm{M}=$ million.

* In 2009, Healthcare Cost and Utilization Project reported 5710 hospitalizations at \$48,900 per patient.

injury from screw malposition..$^{25}$ Similarly, neurological and vascular injury have been reported from severely malpositioned pedicle screws. ${ }^{15}$ Since reliable data regarding the incidence of such events are not available, these were not included as factors in our model.

Finally, we assumed that there was no clinical benefit from using a high-density construct over a standard-density construct. There is a theoretical risk of increased pseudoarthroses and revision rates using a low implant density construct, but this has not yet been addressed in the literature. Further work is needed to verify that there are an equivalent clinical results using standard-density pedicle screw instrumentation.

\section{Additional Literature on the Cost Savings From Using Low Implant Density}

A recent poster presentation estimated $\$ 11$ million to \$20 million in US annual savings by changing from allpedicle screws to an alternating screw pattern, ${ }^{9}$ which sup- ports our results. Yang et al. demonstrated a statistically significant positive association between increased spending on implants per level fused and the percent Cobb angle correction; however, they found no clinically measurable differences in outcomes based on the surgeons' assessment of clinical photos. ${ }^{57}$ Other studies of predominantly screw constructs have not found a significant difference in curve correction or other parameters. ${ }^{32,34,48,50}$

\section{Conclusions}

Should low and high screw-density patterns be determined to have similar clinical and radiographic results, as shown by this model, even a modest reduction in the number of screws may result in significant cost savings of $4 \%$ to $7 \%$ for the payer. In addition, fewer malpositioned screws and a decreased return to surgery for screw malposition may improve patient safety and the quality of surgical care. Additional studies are necessary to determine if

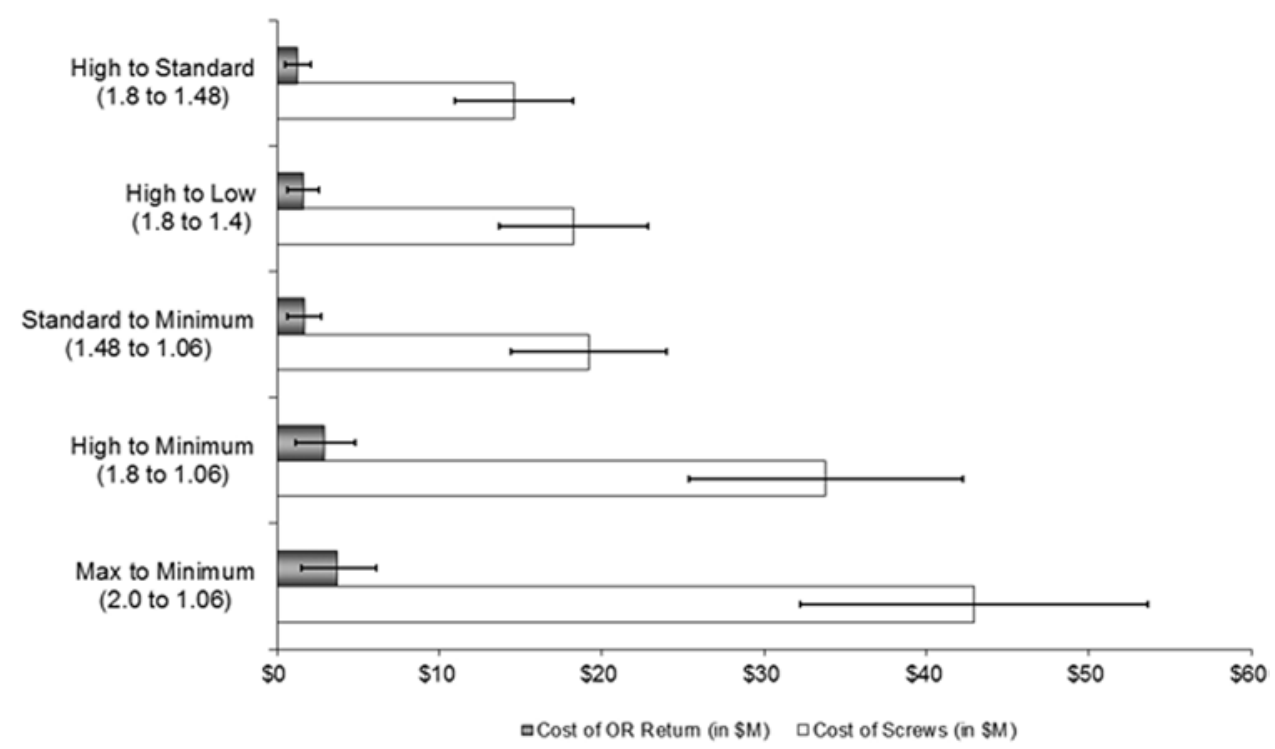

FIG. 2. The majority of anticipated cost savings from reducing the number of screws used results from decreased implant costs rather than savings from averted returns to the operating room (OR) for screw malposition. The $y$-axis shows the screw density, with the number of screws per level fused shown in parentheses. The bars represent the mean cost of returning to the OR, and the whiskers indicate the standard deviation. $\mathrm{M}=$ million. 


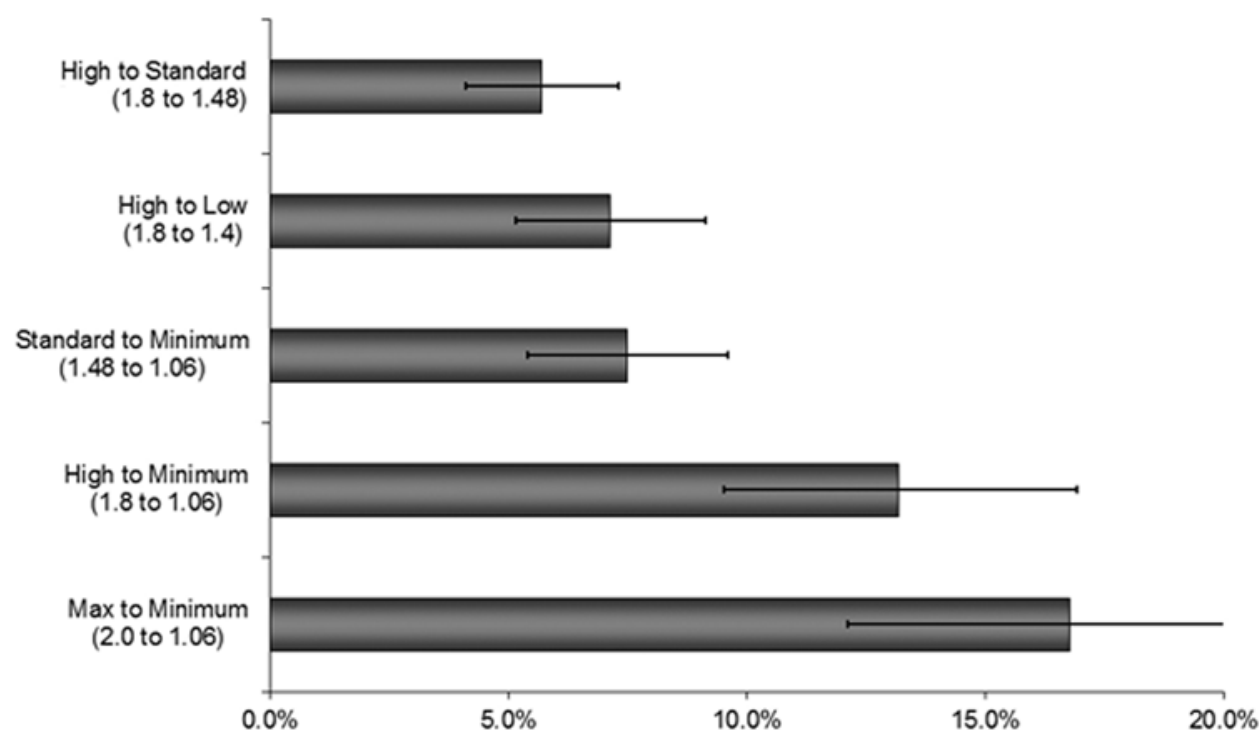

FIG. 3. Switching from a maximum (2.0) to minimum (1.06) implant density pattern would decrease the costs of scoliosis surgery by upwards of $15 \%$, assuming equivalent clinical results.

a low implant density construct provides equivalent results to standard or high implant density constructs.

\section{Acknowledgment}

This study was funded by the Scientific Forum/Spine Care grant from the Orthopaedic Research and Education Foundation and represents work by the Minimize Implants Maximize Outcomes Study Group.

\section{References}

1. Adogwa O, Parker SL, Shau D, Mendelhall SK, Aaronson O, Cheng J, et al: Cost per quality-adjusted life year gained of revision fusion for lumbar pseudoarthrosis: defining the value of surgery. J Spinal Disord Tech 28:101-105, 2015

2. Adogwa O, Parker SL, Shau DN, Mendenhall SK, Aaronson $\mathrm{O}$, Cheng JS, et al: Cost per quality-adjusted life year gained of revision neural decompression and instrumented fusion for same-level recurrent lumbar stenosis: defining the value of surgical intervention. J Neurosurg Spine 16:135-140, 2012

3. Amiot LP, Lang K, Putzier M, Zippel H, Labelle H: Comparative results between conventional and computer-assisted pedicle screw installation in the thoracic, lumbar, and sacral spine. Spine (Phila Pa 1976) 25:606-614, 2000

4. Arlet V, Ouellet JA, Shilt J, Shen FH, Wood K, Chan D, et al: Subjective evaluation of treatment outcomes of instrumentation with pedicle screws or hybrid constructs in Lenke Type 1 and 2 adolescent idiopathic scoliosis: what happens when judges are blinded to the instrumentation? Eur Spine J 18:1927-1935, 2009

5. Aubin CE, Labelle H, Chevrefils C, Desroches G, Clin J, Eng AB: Preoperative planning simulator for spinal deformity surgeries. Spine (Phila Pa 1976) 33:2143-2152, 2008

6. Aubin CE, Labelle H, Ciolofan OC: Variability of spinal instrumentation configurations in adolescent idiopathic scoliosis. Eur Spine J 16:57-64, 2007

7. Belmont PJ Jr, Klemme WR, Robinson M, Polly DW Jr: Accuracy of thoracic pedicle screws in patients with and without cornal plane spinal deformities. Spine (Phila Pa 1976) 27:1558-1566, 2002

8. Bharucha NJ, Lonner BS, Auerbach JD, Kean KE, Trobisch PD: Low-density versus high-density thoracic pedicle screw constructs in adolescent idiopathic scoliosis: do more screws lead to a better outcome? Spine J 13:375-381, 2013

9. Bhat SB, Rendon N, Drummond DS, Flynn JM, Spiegel DA: Cost analysis of implants for surgical correction of scoliosis: implications of construct design. Presented at the American Academy of Orthopaedic Surgeons 2012 Annual Meeting, San Francisco, CA, 2012 (Poster) (http://www.abstractsonline.com/Plan/ViewAbstract. aspx?mID=2841\&sKey=4c4da67c-2453-4194-8e2bffad2f75cece \&cKey=9b332823-520a-40c7-aac4aclebc0db530\&mKey=BA8AA154-A9B9-41F9-91A7F4A4CB050945) [Accessed June 29, 2015]

10. Bridwell KH: Surgical treatment of idiopathic adolescent scoliosis. Spine (Phila Pa 1976) 24:2607-2616, 1999

11. Brown CA, Lenke LG, Bridwell KH, Geideman WM, Hasan SA, Blanke K: Complications of pediatric thoracolumbar and lumbar pedicle screws. Spine (Phila Pa 1976) 23:1566-1571, 1998

12. Carreon LY, Puno RM, Lenke LG, Richards BS, Sucato DJ, Emans JB, et al: Non-neurologic complications following surgery for adolescent idiopathic scoliosis. J Bone Joint Surg Am 89:2427-2432, 2007

13. Cuartas E, Rasouli A, O'Brien M, Shufflebarger HL: Use of all-pedicle-screw constructs in the treatment of adolescent idiopathic scoliosis. J Am Acad Orthop Surg 17:550-561, 2009

14. Di Silvestre M, Parisini P, Lolli F, Bakaloudis G: Complications of thoracic pedicle screws in scoliosis treatment. Spine (Phila Pa 1976) 31:2400-2404, 2007

15. Diab M, Smith AR, Kuklo TR : Neural complications in the surgical treatment of adolescent idiopathic scoliosis. Spine (Phila Pa 1976) 32:2759-2763, 2007

16. Dobbs MB, Lenke LG, Kim YJ, Kamath G, Peelle MW, Bridwell KH: Selective posterior thoracic fusions for adolescent idiopathic scoliosis: comparison of hooks versus pedicle screws. Spine (Phila Pa 1976) 31:2400-2404, 2006

17. Dobbs MB, Lenke LG, Kim YJ, Luhmann SJ, Bridwell KH: Anterior/posterior spinal instrumentation versus posterior instrumentation alone for the treatment of adolescent idiopathic scoliotic curves more than 90 degrees. Spine (Phila Pa 1976) 31:2386-2391, 2006

18. Gebhart S, Alton TB, Bompadre V, Krengel WF: Do anchor density or pedicle screw density correlate with short-term 
outcome measures in adolescent idiopathic scoliosis surgery? Spine (Phila Pa 1976) 39:E104-E110, 2014

19. Heini P, Schöll E, Wyler D, Eggli S: Fatal cardiac tamponade associated with posterior spinal instrumentation. A case report. Spine (Phila Pa 1976) 23:2226-2230, 1998

20. Hicks JM, Singla A, Shen FH, Arlet V: Complications of pedicle screw fixation in scoliosis surgery: a systematic review. Spine (Phila Pa 1976) 35:E465-E470, 2010

21. Hwang CJ, Lee CK, Chang BS, Kim MS, Yeom JS, Choi JM: Minimum 5-year follow-up results of skipped pedicle screw fixation for flexible idiopathic scoliosis. J Neurosurg Spine 15:146-150, 2011

22. Jofe MH, Jofe ED, Cohen RB: Reducing cost without compromising outcome in spinal instrumentation of Lenke 1 adolescent idiopathic scoliosis, in 2010 Pediatric Orthopaedic Society of North America Annual Meeting. Rosemont, IL: POSNA, 2010, p 132, Abstract \#PAPR-41

23. Kakkos SK, Shepard AD: Delayed presentation of aortic injury by pedicle screws: report of two cases and review of the literature. J Vasc Surg 47:1074-1082, 2008

24. Kamerlink JR, Quirno M, Auerbach JD, Milby AH, Windsor L, Dean L, et al: Hospital cost analysis of adolescent idiopathic scoliosis correction surgery in 125 consecutive cases. J Bone Joint Surg Am 92:1097-1104, 2010

25. Kim YJ, Lenke LG, Cho SK, Bridwell KH, Sides B, Blanke $\mathrm{K}$ : Comparative analysis of pedicle screw versus hook instrumentation in posterior spinal fusion of adolescent idiopathic scoliosis. Spine (Phila Pa 1976) 29:2040-2048, 2004

26. Kim YJ, Lenke LG, Kim J, Bridwell KH, Cho SK, Cheh G, et al: Comparative analysis of pedicle screw versus hybrid instrumentation in posterior spinal fusion of adolescent idiopathic scoliosis. Spine (Phila Pa 1976) 31:291-298, 2006

27. Koktekir E, Ceylan D, Tatarli N, Karabagli H, Recber F, Akdemir G: Accuracy of fluoroscopically-assisted pedicle screw placement: analysis of 1,218 screws in 198 patients. Spine J 14:1702-1708, 2014

28. Kuklo TR, Potter BK, Lenke LG, Polly DW Jr, Sides B, Bridwell KH: Surgical revision rates of hooks versus hybrid versus screws versus combined anteroposterior spinal fusion for adolescent idiopathic scoliosis. Spine (Phila Pa 1976) 32:2258-2264, 2007

29. Larson AN, Santos ER, Polly DW Jr, Ledonio CG, Sembrano JN, Mielke CH, et al: Pediatric pedicle screw placement using intraoperative computed tomography and 3-dimensional image-guided navigation. Spine (Phila Pa 1976) 37:E188E194, 2012

30. Ledonio CG, Polly DW Jr, Vitale MG, Wang Q, Richards BS: Pediatric pedicle screws: comparative effectiveness and safety: a systematic literature review from the Scoliosis Research Society and the Pediatric Orthopaedic Society of North America task force. J Bone Joint Surg Am 93:1227-1234, 2011

31. Lenke LG, Kuklo TR, Ondra S, Polly DW Jr: Rationale behind the current state-of-the-art treatment of scoliosis (in the pedicle screw era). Spine (Phila Pa 1976) 33:1051-1054, 2008

32. Li M, Shen Y, Fang X, Ni J, Gu S, Zhu X, et al: Coronal and sagittal plane correction in patients with Lenke 1 adolescent idiopathic scoliosis: a comparison of consecutive versus interval pedicle screw placement. J Spinal Disord Tech 22:251-256, 2009

33. Liljenqvist U, Lepsien U, Hackenberg L, Niemeyer T, Halm $\mathrm{H}$ : Comparative analysis of pedicle screw and hook instrumentation in posterior correction and fusion of idiopathic thoracic scoliosis. Eur Spine J 11:336-343, 2002

34. Lonner BS, Auerbach JD, Boachie-Adjei O, Shah SA, Hosogane N, Newton PO: Treatment of thoracic scoliosis: are monoaxial thoracic pedicle screws the best form of fixation for correction? Spine (Phila Pa 1976) 34:845-851, 2009

35. Lonstein JE, Denis F, Perra JH, Pinto MR, Smith MD, Win- ter RB: Complications associated with pedicle screws. J Bone Joint Surg Am 81:1519-1528, 1999

36. Motiei-Langroudi R, Sadeghian H: Assessment of pedicle screw placement accuracy in thoracolumbosacral spine using freehand technique aided by lateral fluoroscopy: results of postoperative computed tomography in 114 patients. Spine J 15:700-704, 2015

37. Papin P, Arlet V, Marchesi D, Rosenblatt B, Aebi M: Unusual presentation of spinal cord compression related to misplaced pedicle screws in thoracic scoliosis. Eur Spine J 8:156-159, 1999

38. Parker SL, McGirt MJ, Farber SH, Amin AG, Rick AM, Suk I, et al: Accuracy of free-hand pedicle screws in the thoracic and lumbar spine: analysis of 6816 consecutive screws. Neurosurgery 68:170-178, 2011

39. Parker SL, Shau DN, Mendenhall SK, McGirt MJ: Factors influencing 2-year health care costs in patients undergoing revision lumbar fusion procedures. J Neurosurg Spine 16:323-328, 2012

40. Pusic AL, Klassen AF, Cano SJ: Use of the BREAST-Q in clinical outcomes research. Plast Reconstr Surg 129:166e167 e, 2012

41. Roach JW, Mehlman CT, Sanders JO: "Does the outcome of adolescent idiopathic scoliosis surgery justify the rising cost of the procedures?" J Pediatr Orthop 31 (1 Suppl):S77S80, 2011

42. Rose PS, Lenke LG, Bridwell KH, Mulconrey DS, Cronen GA, Buchowski JM, et al: Pedicle screw instrumentation for adult idiopathic scoliosis: an improvement over hook/hybrid fixation. Spine (Phila Pa 1976) 34:852-858, 2009

43. Sanders JO, Diab M, Richards SB, Lenke LG, Johnston CE, Emans JB, et al: Fixation points within the main thoracic curve: does more instrumentation produce greater curve correction and improved results? Spine (Phila Pa 1976) 36:E1402-E1406, 2011

44. Sarlak AY, Tosun B, Atmaca H, Sarisoy HT, Buluç L: Evaluation of thoracic pedicle screw placement in adolescent idiopathic scoliosis. Eur Spine J 18:1892-1897, 2009

45. Smucny M, Lubicky JP, Sanders JO, Carreon LY, Diab M: Patient self-assessment of appearance is improved more by all pedicle screw than by hybrid constructs in surgical treatment of adolescent idiopathic scoliosis. Spine (Phila Pa 1976) 36:248-254, 2011

46. Sucato DJ, Duchene C: The position of the aorta relative to the spine: a comparison of patients with and without idiopathic scoliosis. J Bone Joint Surg Am 85-A:1461-1469, 2003

47. Suk SI, Kim WJ, Lee SM, Kim JH, Chung ER: Thoracic pedicle screw fixation in spinal deformities: are they really safe? Spine (Phila Pa 1976) 26:2049-2057, 2001

48. Suk SI, Lee CK, Kim WJ, Chung YJ, Park YB: Segmental pedicle screw fixation in the treatment of thoracic idiopathic scoliosis. Spine (Phila Pa 1976) 20:1399-1405, 1995

49. Suk SI, Lee CK, Min HJ, Cho KH, Oh JH: Comparison of Cotrel-Dubousset pedicle screws and hooks in the treatment of idiopathic scoliosis. Int Orthop 18:341-346, 1994

50. Tao F, Zhao Y, Wu Y, Xie Y, Li M, Lu Y, et al: The effect of differing spinal fusion instrumentation on the occurrence of postoperative crankshaft phenomenon in adolescent idiopathic scoliosis. J Spinal Disord Tech 23:e75-e80, 2010

51. Ughwanogho E, Patel NM, Baldwin KD, Sampson NR, Flynn JM: Computed tomography-guided navigation of thoracic pedicle screws for adolescent idiopathic scoliosis results in more accurate placement and less screw removal. Spine (Phila Pa 1976) 37:E473-E478, 2012

52. Ul Haque M, Shufflebarger HL, O’Brien M, Macagno A: Radiation exposure during pedicle screw placement in adolescent idiopathic scoliosis: is fluoroscopy safe? Spine (Phila Pa 1976) 31:2516-2520, 2006 
53. Vora V, Crawford A, Babekhir N, Boachie-Adjei O, Lenke $\mathrm{L}$, Peskin $\mathrm{M}$, et al: A pedicle screw construct gives an enhanced posterior correction of adolescent idiopathic scoliosis when compared with other constructs: myth or reality. Spine (Phila Pa 1976) 32:1869-1874, 2007

54. Wang X, Aubin CE, Larson AN, Labelle H, Parent S: Biomechanical analysis of pedicle screw density in spinal instrumentation for scoliosis treatment: first results. Stud Health Technol Inform 176:303-306, 2012

55. Watanabe K, Yamazaki A, Hirano T, Izumi T, Sano A, Morita $\mathrm{O}$, et al: Descending aortic injury by a thoracic pedicle screw during posterior reconstructive surgery: a case report. Spine (Phila Pa 1976) 35:E1064-E1068, 2010

56. Watkins RG IV, Gupta A, Watkins RG III: Cost-effectiveness of image-guided spine surgery. Open Orthop J 4:228-233, 2010

57. Yang S, Jones-Quaidoo SM, Eager M, Griffin JW, Reddi V, Novicoff W, et al: Right adolescent idiopathic thoracic curve (Lenke $1 \mathrm{~A}$ and $\mathrm{B}$ ): does cost of instrumentation and implant density improve radiographic and cosmetic parameters? Eur Spine J 20:1039-1047, 2011

\section{Disclosure}

The authors report the following. Dr. Richards owns stock in Pfizer, receives non-study-related clinical or research support from Biomet, Medtronic, DePuy Synthes, and Stryker; receives travel expenses from Biomet, Medtronic, DePuy Synthes, and Stryker; receives a presidential stipend from the Scoliosis Research Society; and is involved in planning meetings for the Association of Collaborative Research. Dr. Shah is a consultant for DePuy Synthes Spine, received clinical or research support for the described study from the Setting Scoliosis Straight Foundation (aka Harms Study), and owns stock in Globus Medical. Dr. Ledonio has a financial relationship with Medtronic and receives non-study-related research support from Medtronic, SI-Bone, DOD, and OREF through the University of Minnesota. Dr. Lonner is an employee at Mount Sinai Beth Israel Medical Center; is a consultant for DePuy Synthes; owns stock in Paradigm Spine and Spine Search; receives non-study-related clinical or research support from the Setting Scoliosis Straight Foundation (with funding from DePuy Synthes), AOSpine, the John and Marcella Fox Fund, and OREF; serves on the scientific advisory board of DePuy Synthes; serves on the board of directors of Spine Search; is part of the speaker's bureau for DePuy Synthes and K2M; and receives royalties from DePuy Synthes. Dr. Ackerman is a consultant to the medical device industry through employment at Covance. Dr. Emams is a consultant for DePuy Synthes and Medtronic, and receives royalties for VEPTR II.

\section{Author Contributions}

Conception and design: Larson, Polly, Lonner, Shah, Emans, Richards. Acquisition of data: Larson. Analysis and interpretation of data: Larson, Polly, Ackerman, Ledonio, Shah, Emans, Richards. Drafting the article: Larson, Ledonio. Critically revising the article: Larson, Polly, Ackerman, Ledonio, Lonner, Richards. Reviewed submitted version of manuscript: all authors. Approved the final version of the manuscript on behalf of all authors: Larson. Statistical analysis: Ackerman. Administrative/ technical/material support: Larson, Polly, Ledonio. Study supervision: Polly.

\section{Correspondence}

A. Noelle Larson, Orthopaedic Surgery, Mayo Clinic, 200 1st St. SW, Rochester, MN 55905. email: larson.noelle@mayo.edu. 